Bangladesh J. Zool. 40(2): 189-196, 2012

\title{
THE BIOLOGY OF FLESH FLY, BOETTCHERISCA PEREGRINA (ROBINEAU-DESVOIDY, 1830) (DIPTERA: SARCOPHAGIDAE)
}

\author{
M.Z.R. Majumder, Mohan Kumar Dash¹, Rafia Akhtar Khan \\ and Humayun Reza Khan ${ }^{1}$ \\ Radiation Entomology and Acarology Division, Institute of Food and Radiation \\ Biology (IFRB), Atomic Energy Research Establishment (AERE), Ganakbari, \\ Savar, Dhaka, Bangladesh
}

\begin{abstract}
The biology of Boettcherisca peregrina (Robineau-Desvoidy, 1830) (Diptera: Sarcophagidae) was studied in the laboratory $\left(25 \pm 5^{\circ}\right.$ C, R.H. $70 \pm 10 \%$ and $12 \mathrm{~h}$ light: $12 \mathrm{~h}$ dark cycle ). There were four definite life stages, such as egg, larva, pupa and adult, in its life cycle. The mean duration of the life cycle was $13.19 \pm 1.32$ days. The egg was creamy white color, cylindrical, rounded at both ends. The egg shell was comparatively thick and hard. There were three larval instars. The larvae of $B$. peregrina were acephalous and apodus type. The transparent 12 segmented larva possessed a pair of mouth hook, bands of small backwardly directed black micro spines, a pair of prothorasic spiracle and a pair of posterior spiracle. The $1^{\text {st }}$ larvae were relatively more transparent at the time of hatching. The second instar larvae were voracious feeder. The body size increased largely during the third instar. They were deep creamy to pale brownish in color. The pupae of $B$. peregrina were coarctate adecticous type. The posterior end of the puparium was rounded and the anterior end was slightly pointed. The adults were metallic brown in color. The males were smaller in size than the females. The mean incubation period was $11.6 \pm 2.70$ hours, and the larval, post-feeding and pupal periods were $102.22 \pm 7.85$ hours, $75.4 \pm 3.57$ hours, and $5.81 \pm 1.30$ days, respectively. The longevity of the mated male and female adults (36.9 \pm 2.46 days and $27.2 \pm 2.25$ days, respectively) were more than that of the unmated ones $(23.6 \pm 2.25$ days and $18.3 \pm 1.5$ days, respectively). The protein fed adults lived longer than the protein unfed ones.The male always lived longer than the female.
\end{abstract}

Key words: Biology, life cycle, Boettcherisca peregrina, Sarcophagidae.

\section{INTRODUCTION}

Boettcherisca peregrina (Robineau-Desvoidy, 1930) (Diptera: Sarcophagidae), commonly known as flesh fly, has medical and veterinary importance as an ectoparasite causing myiasis in human and other mammals. Recently, the flies are used in medio-criminal entomology. They are large-sized flies with black and gray longitudinal stripes on the thorax, and a checkerboard-like pattern on abdomen, which often red-tipped. The eyes are brightly red. Females are larviparous. These flies are strong fliers.

In Bangladesh, B. peregrina has great significance for human hygiene and also in the economy of the livestock myiasis, fish and other animal food processing factories. The larvae of this species take nourishment from exposed

1Department of Zoology, University of Dhaka, Dhaka-1000, Bangladesh. 
fish and meat, and contaminate the food material by reducing the nutritional value of the food materials. Lucilia cuprina is the key pest of the fish drying industries of the coastal and off-shore islands in the Bay of Bengal. Boettcherisca peregrina is also a common pest on the same area. Together with the key pest they harm a lot of existing fish industries.

There are three important insect pests of sun-dried marine fish, viz. $B$. peregrina, Chrysomya megacephala and L. cuprina. At present, the feasibility study of the blowfly Sterile Insect Technique (SIT) is being continued at Sonadia and Nazirer Tek marine fish drying yard in order to suppress the major pest, $L$. cuprina. Preliminary results of the field level application of the blowfly SIT showed a gradual suppression of the wild population of $L$. cuprina in the targeted localities. The present study on the general biology of $B$. peregrina will be of great value towards the development of suitable control measures including SIT.

\section{MATERIAL AND METHODS}

The biology of the fly was studied in the blowfly laboratory of the Radiation Entomology and Acarology Division, Institute of Food and Radiation Biology (IFRB), Atomic Energy Research Establishment (AERE), Savar, Dhaka. An adult stock rearing of $B$. peregrina was maintained in the laboratory condition (25 \pm $5^{\circ} \mathrm{C}, 70 \pm 10 \%$, R.H. and $12 \mathrm{~h}$ light: $12 \mathrm{~h}$ dark cycle). Adult stock was kept in rectangular cages made up of wood and iron frame $(30 \times 20 \times 20 \mathrm{~cm})$ covered with nylon mosquito net. They were supplied with a solution of sugar and water soaked in cotton wools as their food.

Fresh bovine liver was supplied to the adult flies for proper reproductive development. Initially, small pieces of fresh cow liver were given which helped the growth of their reproductive system. Later on, tilapia fish (Oreochromis niloticus) were given as their food which was placed in a petridish inside the stock cage for the collection of eggs and larvae. Normally, the females were viviparous laying the $1 \mathrm{~s}^{\mathrm{t}}$ instar larvae. Occasionally, the females laid eggs in clusters. The eggs and $1^{\text {st }}$ instar larvae were then put on a fish placed in a small bowl the fish being used as their food. The fishes containing the larvae were then placed in a larger plastic bowl with sawdust at the base. The large bowl was then covered with a piece of cloth primarily to prevent from external invasion by the same or other fly species.

Some larvae of $B$. peregrina were placed on a petridish to observe different characterstics of the larval instars after each ecdysis. Five replications were used. Prior to pupation the late $3^{\text {rd }}$ instar larva stopped feeding and dropped onto the saw dust and remained in the saw dusts till the formation of pupae 
and this stage is called the post feeding larval stage. The pupae were isolated from the saw dust by hand sieving. The clean pupae kept in a petridish and were placed in the adult cages for emergence into the adult flies of the next generation. Different changes of morphological features and color of various life stages were recorded under a light microscope and micro photograph was taken by using a Nikon microscope. The length and breadth of the larvae were measured by an ocular micrometer. The longevity of the adults was observed on two different food media (Sugar, Water and Liver or Sugar and Water) either in paired or unpaired conditions. For this, ten pairs of male and female were placed in each adult cage for rearing. The emerged males and females were utilized for laboratory culture and other experimental purposes.

\section{RESULTS AND DISCUSSION}

The life cycle of $B$. peregrina comprised of four definite stages, such as egg, larva, pupa and adult (Fig. 2).

Egg (Fig. 1): The egg of $B$. peregrina was creamy white in color, cylindrical, rounded at both ends; the anterior end was more tapered than posterior end. The shell or chorion of the egg was comparatively thick and hard. The creamy white egg considerably attained a deeper creamy coloration prior to hatching. Under light microscope, segmental dark bands and black pointed mouth hook of the developing larva could be seen through the transparency of the chorion. The moisture played an important role in the hatching of the larvae. The incubation period of the flesh fly was $11.6 \pm 2.7$ hours (Table 1). The average length and breadth of the egg of $B$. peregrina were $1.61 \pm 0.13 \mathrm{~mm}$ and $0.44 \pm 0.039 \mathrm{~mm}$, respectively (Table 2 ).

The present results were in conformity with the findings of David et al. (2003) and Sukontason et al. $(2007,2005)$.

Larva (Fig. 1): The larva of $B$. peregrina was acephalous and apodous type which had three instars. Each instar was transformed into the following instar by shedding off their old skin (exuvium). The transparent 12 segmented larva possessed a pair of mouth hook, bands of small backwardly directed black micro spines, a pair of prothoraxic spiracle and a pair of posterior spiracle. The tracheal and digestive systems of the larva were visible under the microscope through transparent body cuticle. They could move by means of the expansion and contraction of their segmented legless body.

First instar larva (Fig. 1): The $1^{\text {st }}$ instar larva was relatively more transparent at the time of hatching. The mean length and breadth of the larva was $1.77 \pm$ $0.024 \mathrm{~mm}$ and $0.50 \pm 0.107 \mathrm{~mm}$, respectively (Table 2). In most cases, the female flies laid first instar larva on or near the food sources. 

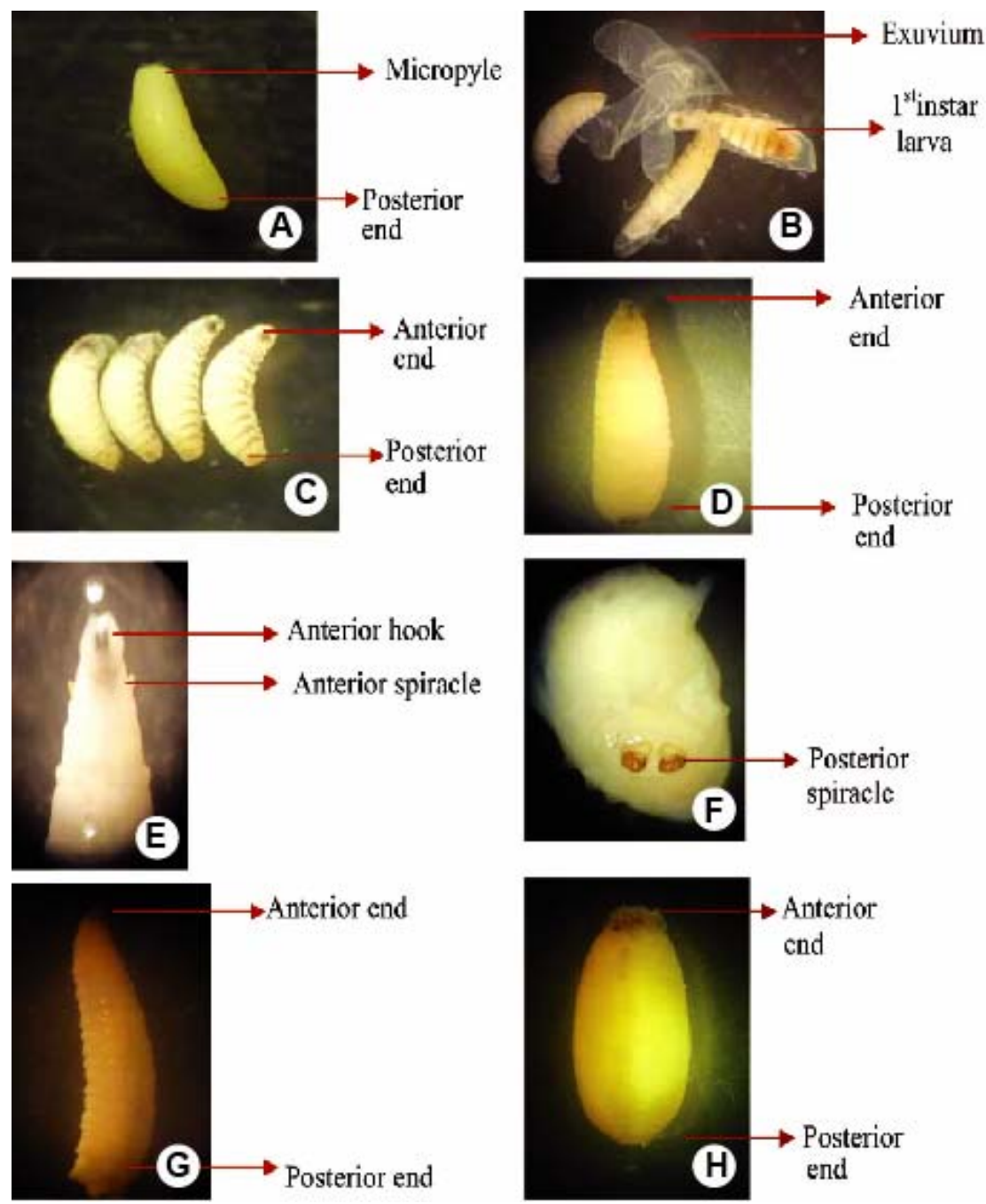

Fig. 1. Photograph showing A) egg; B) $1^{\text {st }}$ instar larva hatching out; C) $1^{\text {st }}$ instar larvae; D)2 $2^{\text {nd }}$ instar larva; E) Anterior hook of $3^{\text {rd }}$ instar larva; F) Posterior spiracle of $3^{\text {rd }}$ instar larva; G) $3^{\text {rd }}$ instar larva and $\mathrm{H}$ ) early stage of pupa of $B$. peregrina. (Magnification=2X).

Second instar larva (Fig. 1): The second instar larvae were voracious feeder. The mean length and breadth of the $2^{\text {nd }}$ instar larvae were $4.49 \pm 0.22 \mathrm{~mm}$ and $0.97 \pm 0.088 \mathrm{~mm}$, respectively (Table 2 ).

Third instar larva (Fig. 1): The body size of the third instar larva increased largely, but the overall morphological features were the same as those of the second instar larva. It was deep creamy to pale brownish in color. The mean length and breadth of the $3^{\text {rd }}$ instar larva was $21 \pm 0.98 \mathrm{~mm}$ and $4.76 \pm 0.36 \mathrm{~mm}$, respectively (Table 2). 


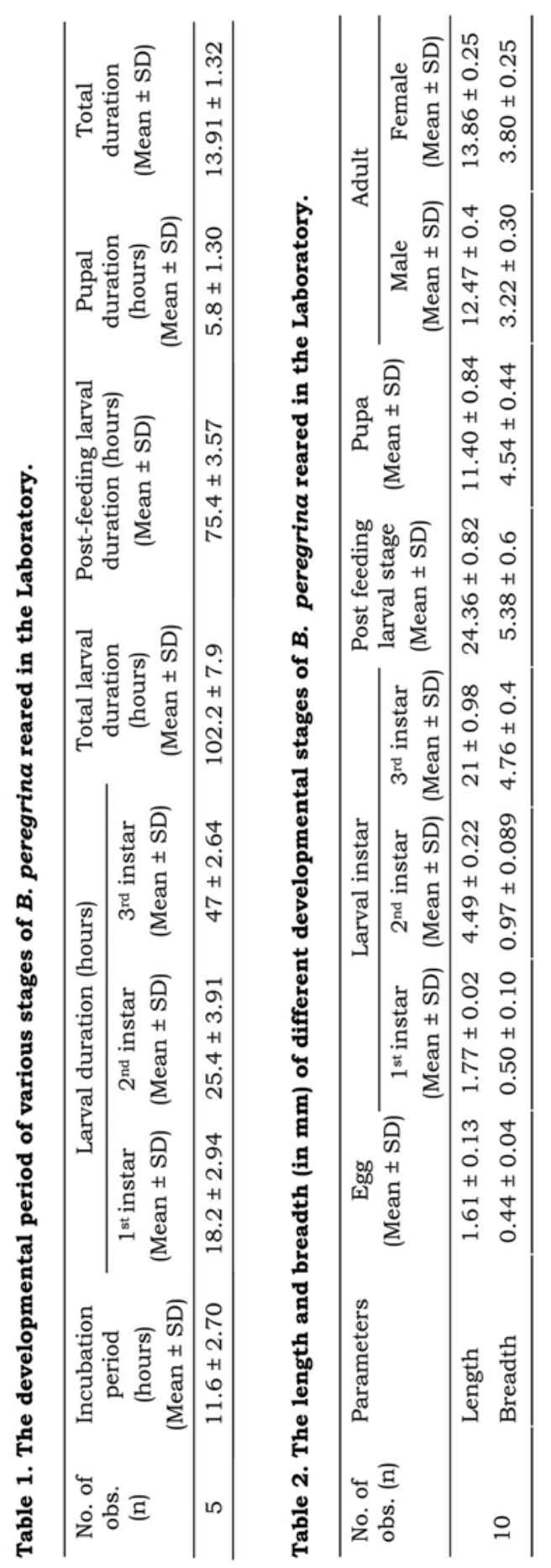


Larval period: The total larval period, i.e. from first larval hatching to post feeding pre-pupal stage, was of 102.2 \pm 7.85 hours (Table 1).

These findings on the larval morphology of $B$. peregrina were also observed by other contemporary scientists as Queiroz and Carvalho (1987), Queiroz et al. (1997) and Parkar (1916).

Post-feeding larval stage: At the end of the third instar larval stage, the larva stoped feeding and droped into the saw dust, and passed on to an inactive stage. During this period, the larva became thicker and shorter, and the cuticle gradually contracted, hardened and darkened to form puparium. The average duration of this stage was $75.4 \pm 3.57$ hours (Table 1). The average length and breadth of the post-feeding larva were $24.36 \pm 0.816 \mathrm{~mm}$ and $5.38 \pm 0.559 \mathrm{~mm}$, respectively (Table 2 ).

Pupa and pupal period (Fig. 2): The pupae of B. peregrina were coarctate adecticous type. The posterior end of the puparium was rounded and the anterior end was slightly pointed. Some of the non-functional features were observed on the puparium like bands of spines, black sclerotized mouth-hook, anterior spiracles, posterior spiracles, etc. The color of the pupa was creamy white at the initial stage and later turned into red brown to blackish brown color after a few hours or a day when sclerotization was completed. The average pupal period of the flesh fly was $5.8 \pm 1.30$ days (Table 1 ). The average length and breadth of the pupa were $11.40 \pm 0.84 \mathrm{~mm}$ and $4.54 \pm 0.44 \mathrm{~mm}$, respectively (Table 2). The results of the study had similarity with the findings of Janjua (1948).

Adult (Fig. 2): The ptilinum of the mature adult broke the puparium during emergence. The newly emerged flies were at first very soft, grayish black in color with ptilinum and unexpanded wings. Within a few hours, the ptilinum was inverted; the cuticle hardened and the wings were expanded to dry. They were turned to metallic brown in color. The males usually emerged earlier than the females. The males were smaller in size than the adult females.

The mean length and breadth of the males were $3.11 \pm 0.0089 \mathrm{~mm}$ and $0.805 \pm 0.07 \mathrm{~mm}$, respectively and those of the females were $3.46 \pm 0.0625 \mathrm{~mm}$ and $0.95 \pm 0.0645 \mathrm{~mm}$, respectively at the thoracic region (Table 2).

Duration of life cycle: The total duration of the life cycle (from egg to adult) of B. peregrina was $13.19 \pm 1.32$ days (Table 1 ).

Adult longevity: The mean longevity of the paired male and female reared on liver, sugar and water were $36.9 \pm 2.46$ days and $27.2 \pm 2.25$ days, respectively and that of the unpaired male and female feeding on the same food, were $23.6 \pm$ 2.25 days and $18.3 \pm 1.5$ days, respectively (Table 3 ). The mean longevity of the paired male and female feeding on sugar and water were $29.2 \pm 1.17$ days and 


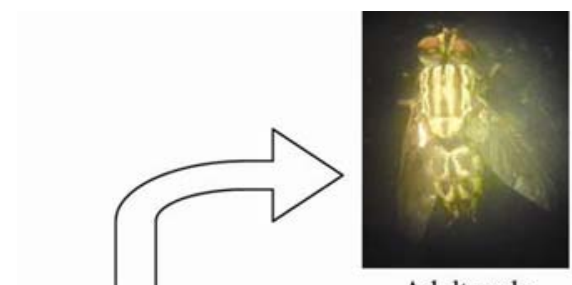

Adult male

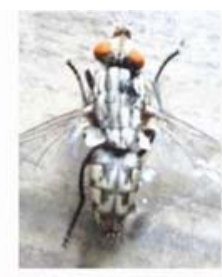

Adult Female

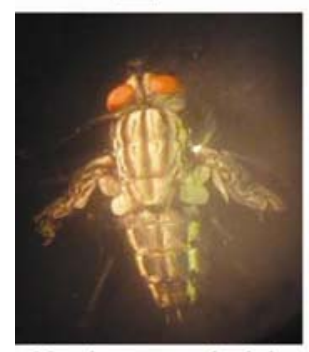

Newly emerged adult

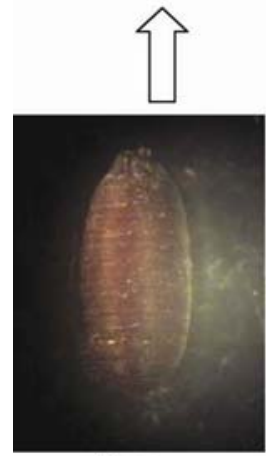

Pupa

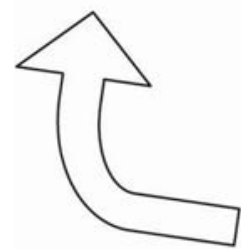

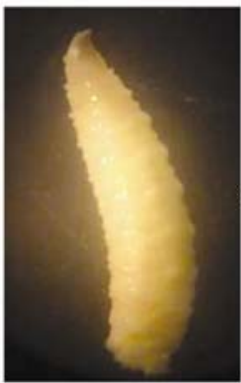

Post-feeding larva

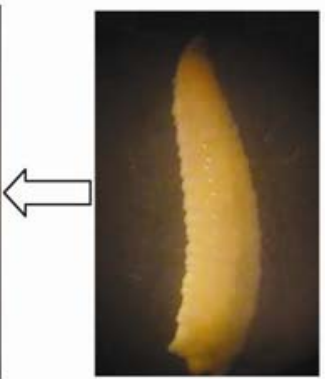

Third instar larva
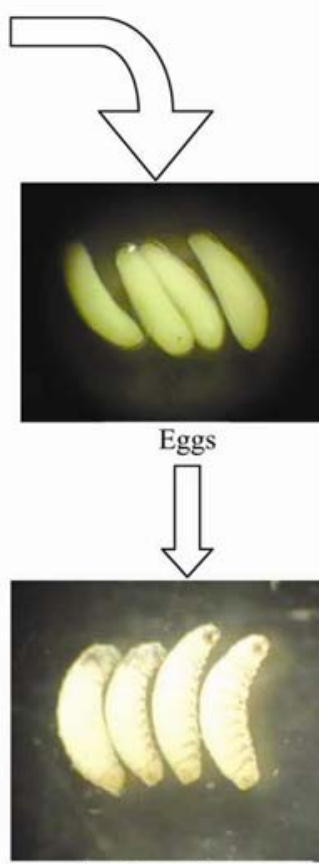

First instar larva

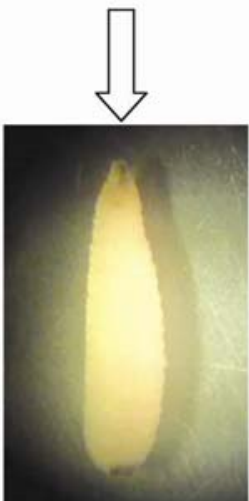

Second instar larva

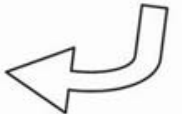

Fig. 2. The life-cycle of $B$. peregrina (Magnification=2x).

$25.5 \pm 1.67$ days, respectively and unpaired male and female feeding on the same food, were $16.8 \pm 1.03$ days and $14.4 \pm 1.26$ days, respectively (Table 3). The variations in dietary proteins, and paired and unpaired conditions influenced the adult longevity of $B$. peregrina. The longevity of the males was 
always greater than the females in both paired and unpaired conditions irrespective of variations in food sources. Gabre et al. (2005) reported that in case of $C$. megacephala, the adult longevity of both males and females feeding on liver was always more prolonged than those reared on the food without liver. Protein rich food, such as fresh bovine liver is essential for the reproductive development of $B$. peregrina.

Table 3. Longevity of the male and female of $B$. peregrina on different food regime.

\begin{tabular}{llcccc}
\hline \multirow{2}{*}{\begin{tabular}{l} 
No. of $\begin{array}{l}\text { obs. (n) } \\
\end{array}$ \\
\cline { 3 - 6 }
\end{tabular}} & \multirow{3}{*}{ Food } & \multicolumn{3}{c}{ Paired } & \multicolumn{2}{c}{ Unpaired } \\
\cline { 3 - 6 } & & $\begin{array}{c}\text { Male } \\
(\text { Mean } \pm \text { SD) }\end{array}$ & $\begin{array}{c}\text { Female } \\
(\text { Mean } \pm \text { SD) }\end{array}$ & $\begin{array}{c}\text { Male } \\
(\text { Mean } \pm \text { SD) }\end{array}$ & $\begin{array}{c}\text { Female } \\
(\text { Mean } \pm \text { SD) }\end{array}$ \\
\hline \multirow{2}{*}{10} & Liver, sugar and water & $36.9 \pm 2.46$ & $27.2 \pm 2.25$ & $23.60 \pm 2.25$ & $18.03 \pm 1.5$ \\
& Sugar and water & $29.2 \pm 1.17$ & $25.5 \pm 1.67$ & $16.8 \pm 1.03$ & $14.4 \pm 1.26$ \\
\hline
\end{tabular}

The present study of $B$. peregrina infesting fresh fish will be very useful for the development of flesh fly SIT through the radio-sterility of male flies, and release of the sterile male in target area to mate with the wild female, and resulting in the hinderance of the natural production of offsprings which will cause gradual suppression of the target pest population.

\section{LITERATURE CITED}

BYRD-DAVID, J.A., DEO ROCHA, T. and CAETANO, F.H. 2003. Eggs ultramorphology of the blowflies Chrysomya megacephala and Chrysomya albiceps. (Diptera: Cailiphoridae). Acta Microscopica 12:111- 112.

GABRE, R.M., ADHAM, F.K. and CHI, H. 2005. Life table of Chrysomya megacephala (Fabricius) (Diptera: Calliphoridae). Acta Oecologica 27: 179- 183.

JANJUA, N. A. 1948. The biology of Dacus (Strumeta) ferrrugineus (Typetidae: Diptera) in Beluchistan. Ind. J. Entomol. 10:55-61.

PARKAR, P. 1916. Biology of Sarcophag bullata. Ann. Ent.Soc. Am. 62 (3): 250-256.

QUEIROZ, M.M.D., MEWLO, R.P.D. and LIMA, M.M.1997. Morphological aspects of the larval instars of Chrysomya albiceps (Diptera: Calliphoridae) reared in the laboratory. Memories do Instituto Oswaldo Cruze 92(2): 187- 196.

QUEIROZ, S.M. and CARVALHO, C.J.B. 1987. Chave pictorial e descricoes de larvas de $3^{\text {rd }}$ inster de Diptera (Calliphoridae. Muscidae e Fannidae) em vazadouros e residuos solidos domesticos em curitiba. PR Ann. Soc. Entomol. Bras.16: 165-188.

SUKONTASON, K.L., VOGTSBERGER, R.C., BOONCHLJ, N., CHAIWONG, T., SRIPAKDEE, D., NGERN-KLUN, R., PIANGJA1, S. and SUKONTASON, K. 2005. Larval morphology of Chrysomya nigripes (Diptera: Calliphoridae), a fly species of forensic importance. J. Med. Entomol. 42(3):233240.

SUKONTASON, K.L., BUNCHU, N., CI-JAIWONG, T., KUNTALUE, B. and SUKONTASON, K. 2007. Fine structure of the eggshell of the blow fly, Lucilia Cuprina. J. Insect Sci. 7(9):220-250. 